\title{
Tetrahydrofuran poisoning after occupational
}

\section{exposure}

\author{
R GARNIER, N ROSENBERG, J M PUISSANT, J P CHAUVET, M L EFTHYMIOU \\ From the Poison Control Centre and the Department of Occupational Health, Hopital Fernand Widal and \\ Université Paris VII, 75475 Paris Cédex 10, France
}

Tetrahydrofuran (THF) is a colourless liquid with a mild ethereal odour. It is miscible with water and most organic solvents. It can dissolve many types of plastics -for instance, polyvinyl chloride, polyurethanes, epoxy compounds, and cellulosics-and a wide range of organic products. Its use is growing steadily. Its main applications include glues, paints, varnishes, inks, and wetting and dispersing agents in textile processing. It is a volatile solvent: its boiling point is $66^{\circ} \mathrm{C}(760 \mathrm{~mm} \mathrm{Hg})$ and its vapour pressure is 176 $\mathrm{mm} \mathrm{Hg}\left(25^{\circ} \mathrm{C}\right)$; therefore high vapour concentrations may develop at the workplace.

THF is readily absorbed across the alveolar membrane and from the digestive tract; it can also cross the skin in toxic amounts. ${ }^{1-4}$ It is believed to have a low toxicity compared with other cyclic ethers. Experimental studies are scanty; to our knowledge, only six papers describe irritating or systemic effects of THF in exposed workers and most of these human cases are only briefly reported. ${ }^{4-10}$

We report two cases of THF poisoning after occupational exposure.

\section{Case 1}

This previously healthy 35 year old man had no history of alcoholism and had taken no drug for the past three months. He was a plumber and had been repairing plastic pipes in a confined space, eight hours daily for three days, when he presented to one of us. He had been using glue containing THF without wearing any protective devices.

At presentation he complained of nausea, headache, blurred vision, dizziness, chest pain, and cough. Clinical examination disclosed conjunctival irritation and a few sibilant rales on pulmonary auscultation. Chest $x$ ray examination and ECG were normal, as were blood cell count, serum creatinine concentration, blood urea nitrogen, bilirubinaemia, serum alkaline phosphatase activity, and prothrombin time. Aspar-

Accepted 31 October 1988 tate aminotransferase (AST) and alanine aminotransferase (AST) activities, however, were found to be three times the upper limit of the normal range.

All clinical symptoms abated within two days. Liver enzymes returned to normal within two weeks. Hepatitis B surface antigen and IgG antihepatitis A virus were not detected.

\section{Case 2}

This 55-year-old man, also a plumber, had earlier been healthy, had never drunk alcohol in excessive amounts, and had received no drugs for several months when he was admitted to our unit. For the past few hours he also had been repairing plastic pipes in a confined space with a glue containing THF and wearing no protective devices.

He complained of headache, dizziness, chest pain, dyspnoea and epigastric pain. Clinical examination, blood cell count, and hepatic and renal functions were normal. On the next day, the patient was in good clinical condition but AST, ALT, and gammaglutamyl transferase (GGT) activities had risen respectively to 25,15 , and nine times the upper limit of normal values. Bilirubinaemia, alkaline phosphatase activity, prothrombin, time, blood urea nitrogen, serum creatinine concentration, and blood cell count remained unchanged. The liver enzymes returned to normal values within two weeks. No other clinical or biological abnormalities were detected during this period. Serological markers of infectious hepatitis were not tested.

\section{Discussion}

These two workers had signs of irritation of mucous membranes, mild effects on the central nervous system, and cytolytic hepatitis after exposure to THF in similarly poor conditions.

Irritation of the skin and mucous membranes has already been described in exposed workers. ${ }^{6}$ On contact with air, THF forms explosive peroxides which may increase the irritating power of the solvent. ${ }^{6}$ In 
rabbits an alteration of tracheal ciliary activity was observed at THF vapour concentrations of $100 \mathrm{ppm}$ and above. " Signs of irritation of eyes and airways appeared at $200 \mathrm{ppm}$ in rats; at $5000 \mathrm{ppm}$ they were severe. ${ }^{3}$ When directly applied on the skin of rabbits, THF aqueous solutions caused severe caustic lesions at solvent concentrations of $50 \%$ and more; at $20 \%$ only moderate skin irritation was noted but severe keratitis was observed when the solution was applied on the eyes; oral administration produced haemorragic and ulcerative gastritis. ${ }^{1}$

Mild central nervous system effects are not rare among workers exposed to $\mathrm{THF}^{4}$ The main complaints appear to be headache and dizziness but fatigue, nausea, and tinnitus have also been reported..$^{468}$ In experimental animals high doses of THF produced coma, myoclonic jerks, and cerebral convulsions. ${ }^{1-351213}$ THF might have contributed to the development of status epilepticus on awakening from an enfluran anaesthesia in a patient occupationally exposed to the solvent. ${ }^{8}$

Fatty infiltration of the liver and cytolytic hepatitis after both single and repeated exposure to THF have been observed in animals. ${ }^{1312}$ Tolot et al reported that liver enzymes were slightly raised in a worker six weeks after an episode of subacute THF poisoning. ${ }^{6}$ Juntunen et al also reported a transient rise of liver enzymes in two instances in a previously healthy patient occupationally exposed to THF ${ }^{8}$ GGT and AST activities were raised in a man exposed to THF together with other potentially hepatotoxic solvents (chloroform and trichloroethylene); liver biopsy showed moderate fatty infiltration and siderosis. ${ }^{9}$ It should be noted that serological markers for the main agents of infectious hepatitis were tested in none of these three published cases.

In experimental animals THF has also been reported to cause a drop in blood pressure ${ }^{57}$ and tubular and glomerular renal damage ${ }^{1}$; it increased the activities of liver and kidney 7-ethoxycoumarin O-deethylase and of muscle acetyl cholinesterase in rats. ${ }^{4}$ It was implicated in one person with peripheral neuropathy. ${ }^{10}$

THF was certainly responsible for the mild effects on the central nervous system and the irritation of mucous membranes in our two patients: both had been exposed to high concentrations of the solvent during a prolonged period and all these symptoms vanished within a few hours after exposure ceased. That THF $\overline{\bar{Q}}$ also produced liver damage in these cases cannot be $z$ unequivocally ascertained as serological markers for $\stackrel{\mathbb{Q}}{\mathscr{Q}}$ the main agents of infectious hepatitis were not tested in case 2 and the biological screening was incomplete in case 1. The rise in liver enzymes, however, waso associated with other signs of THF toxicity in both음 cases; the clinical course was also highly suggestive of an occupational toxic hepatitis as the serum amino- $\frac{\widehat{\Phi}}{\varnothing}$ transferases increase occurred (case 2) or was discovered (case 1) after exposure to high THF vapour ${ }^{\text {C }}$ concentrations and complete recovery rapidly fol- $\vec{\circ}$ lowed eviction of the solvent.

\section{References}

1 Jochmann W. Zur Frage der Schädigung von Leber und Niere 0 durch Tetrahydrofuran. Naunyn Schmierderberg's Archives of Experimental Pathology and Pharmacology 1961;18:689-717. V

2 Zeller Von H, Hofmann HT, Meinecke KH, Oeteel H. Zuro Toxizität von Tetrahydrofuran. Archives of Experimental Pathology and Pharmacology 1964;247:359-60.

3 Katahira T, Teramoto K, Horiguchi S. Experimental studies on $\Theta$ the acute toxicity of tetrahydrofuran in animals. Sangyo Igaku응 1982;24:373-8.

4 Elovaara E, Pfäffli P, Savolainen H. Burden and biochemical effects of extended tetrahydrofuran vapour inhalation of three concentration levels. Acta Pharmacol Toxicol 1984;54:221-6.

5 Stoughton RW, Robbins BH. The anaesthetic properties of $\overrightarrow{0}$ tetrahydrofuran. J Pharmacol Exp Ther 1936;58:171-3.

6 Tolot F, Girard R, Bresson JR, Soubrier R. Accidents causés pa fle. tétrahydrofurane (oedème de Quincke et malaises lip̈thymiques). Rev Med Suisse Romande 1968;88:182-7.

7 Browning E. Toxicology and metabolism of industrial solvents. Amsterdam: Elsevier, 1965:700-1.

8 Juntunen $J$, Kaste $M$, Härkönen $H$. Cerebral convulsion after enfluran anaesthesia and occupational exposure to tetra-(D) hydrofuran. J Neurol Neurosurg Psychiatry 1984;47:1258-9.

9 Edling C. Interaction between drugs and solvents as a cause of $\overrightarrow{0}$ fatty change in the liver. Br J Ind Med 1982;39:198-9.

10 Viader F, Lechevalier B, Morin P. Polynévrite toxique chez un travailleur du plastique. Nouvelle Presse Médicale 1975;4: $1813-4$.

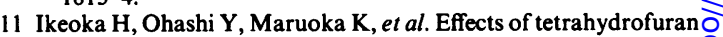
exposure on the ciliary activity and morphology of tracheal $\frac{\mathbb{}}{3}$ epithelium in rabbits. Osaka City Med J 1984;30:53-68.

12 Henderson VE, Smith AHR. Anaesthetic effects of some furan derivatives. J Pharmacol Exp Ther 1936;57:394-8.

13 Marcus RJ, Winters WD, Hultin E. Neuropharmacological effects? induced by butanol, 4 hydroxybutyrate, 4 mercaptobutyric acid thiolactone, tetrahydrofuran, pyrrolidine, 2-deoxy-d-glucose and related substances in the rat. Neuropharmacology 1976;15:29-38. 